\title{
Getting insurance after genetic screening on familial hypercholesterolaemia; the need to educate both insurers and the public to increase adherence to national guidelines in the Netherlands
}

\author{
P J Marang-van de Mheen, M C van Maarle, M E A Stouthard
}

J Epidemiol Community Health 2002;56:145-147

Heterozygous familial hypercholesterolaemia (FH) is a common autosomal dominant inherited metabolic disease with a prevalence of 1 in 500 in most Western countries. ${ }^{1-3}$ People with $\mathrm{FH}$ experience an increased risk for coronary artery disease (CAD) and excess mortality especially at a young age. ${ }^{45}$ Until recently the diagnosis of $\mathrm{FH}$ was based on clinical signs and symptoms alone. These included increased cholesterol concentrations, in particular of LDL-cholesterol, in combination with the presence of tendon xanthoma, corneal arcus, xanthelasmata and a history of early $\mathrm{CAD}$. Frequently $\mathrm{FH}$ was diagnosed after a first cardiac event.

See end of article for authors' affiliations

Correspondence to: Dr P J Marang-van de Mheen, Department of Medical Decision Making, K6-R, Leiden University Medical Centre, PO Box 9600, 2300 RC Leiden, the Netherlands:

p.j.marang-van_de_mheen@ lumc.nl

Accepted for publication 3 July 2001

\section{GENETIC SCREENING}

The discovery of LDL receptor gene mutations in clinically diagnosed familial hypercholesterolaemia $(\mathrm{FH})$ patients and the consequent development of DNA tests for these mutations, enabled the diagnosis of FH in pre-symptomatic patients. In principle, the availability of effective treatment for $\mathrm{FH}$ made screening of relatives of identified FH patients an attractive strategy to reduce the risk of coronary artery disease (CAD).

In 1994, such a family-based genetic screening programme for $\mathrm{FH}$ was implemented in the Netherlands. ${ }^{67}$ This programme is targeted on at risk relatives (over 16 years of age) of clinically diagnosed FH patients with a known mutation in the LDL-receptor gene, also called index patients. First degree relatives of index patients are offered genetic testing for the mutation found in the index patient. If these relatives carry the mutation, their first degree relatives are screened. Mutation carriers are referred to their general practitioner with the advice to have a further specialist examination at a lipid clinic.

\section{SOCIAL CONSEQUENCES OF GENETIC SCREENING}

Participating in such a genetic screening programme may induce other effects than the aimed health benefit because of the reduction of CAD risk. As a result of screening there may be negative social consequences, such as problems with regard to the access to insurance. In the Netherlands, as in most other countries, health insurance is compulsory. The health system in the Netherlands can be classified as a Sickness Insurance model. The Netherlands has developed a mixed health care system in which approximately $70 \%$ of the population is covered for their medical costs (except chronic residential care) through an income related social health insurance, and the remaining $30 \%$ through private health insurance. ${ }^{8}$ Insurance companies do not always accept people who apply for insurance, but a special insurance arrangement is available for persons difficult to insure. If, however, a person has to leave the social health insurance plan as a result of a higher income, national rules enforce acceptance by a private insurer. In the past decade there has been a transition from many sick funds and private health insurers into a few large financial institutions. These companies offer a wide array of work disability and life insurance packages, often in combination with mortgages.

People who apply for insurance have to fill out a health questionnaire. Coverage of claims depends on truthful response to this assessment of prior risks. However, restrictions exist with regard to enquiries about genetic test information. In the Netherlands, a moratorium has been declared on the use of genetic test results. In this moratorium, insurance companies state that below an amount of 300000 Dutch guilders (approximately $£ 85000$ ) for life insurance and below an amount of 60000 Dutch guilders for the first year and 40000 Dutch guilders for the second and following years in work disability insurance, the results of genetic tests do not have to be supplied (including information with regard to the suffering or death of family members because of serious untreatable familial disorders). The Act on Medical Examinations, which came into force in 1998, contains the same conditions.

Many European countries have no legislation or guidelines on insurance and medical examinations with respect to genetic testing. ${ }^{9}$ Other countries (for example, France) have guidelines and have imposed a moratorium on the use of genetic tests. In the UK, guidelines on genetic testing are proposed by the insurance industry, rather than by the government.

The issue of this paper is whether such a moratorium on the use of genetic tests or legislation

Abbreviations: $\mathrm{FH}$, familial hypercholesterolaemia; $\mathrm{CAD}$, coronary artery disease 
Table 1 Problems with insurance related to clinical risk: mutation and cholesterol level

\begin{tabular}{|c|c|c|c|c|}
\hline \multicolumn{2}{|c|}{ Clinical risk } & \multicolumn{2}{|c|}{ Problems } & \multirow[b]{2}{*}{ Total } \\
\hline Mutation & Cholesterol level & No & Yes & \\
\hline No & $\begin{array}{l}\leqslant 6.5 \mathrm{mmol} / \mathrm{I} \\
>6.5 \mathrm{mmol} / \mathrm{l}\end{array}$ & $\begin{array}{l}11 \\
1\end{array}$ & $\begin{array}{l}0 \\
0\end{array}$ & $\begin{array}{l}11 \\
1\end{array}$ \\
\hline Yes & $\begin{array}{l}\leqslant 6.5 \mathrm{mmol} / \mathrm{l} \\
>6.5 \mathrm{mmol} / \mathrm{l}\end{array}$ & $\begin{array}{l}7 \\
10\end{array}$ & $\begin{array}{l}3 \\
14\end{array}$ & $\begin{array}{l}10 \\
24\end{array}$ \\
\hline Total & & 29 & 17 & 46 \\
\hline
\end{tabular}

protects participants of a genetic screening programme from experiencing problems in the access to insurance.

\section{EMPIRICAL STUDY}

We conducted an empirical study among people screened for FH in the Netherlands by the programme mentioned above, in a period in which the moratorium and/or the Act on Medical Examinations were into force. The following questions were addressed:

- to which extent do people screened for $\mathrm{FH}$, run into problems when applying for insurance (depending on the test result);

- which problems were the most prevalent, if any;

- how did problems relate to the medical condition: were problems attributable to a genetic mutation for $\mathrm{FH}$, to an increased cholesterol concentration, or both. We looked at an increased cholesterol concentration as this will be the most likely confounder in this population of mainly asymptomatic carriers and non-carriers.

From approximately 1000 persons screened between 1 January 1994 and 31 December 1997, 350 people aged 20 to 60 years with known test results were selected from the registration. We aimed for an equal distribution of age and gender in the group with $(n=175)$ and without $(n=175)$ a mutation for FH. The age range was chosen for two reasons. Life insurance and mortgages are predominantly relevant for this age range, and cholesterol levels for those aged over 60 often exceed cut off points used by insurance companies.

Administrative data were made available by the organisation responsible for the screening programme (the StOEH foundation). To protect privacy, the StOEH, rather than the investigators, invited selected persons to participate by means of a postal questionnaire. Questionnaires could be returned to the StOEH. One reminder was sent two weeks after the first questionnaire. The study was approved by the medical ethical committee of the Academic Medical Centre.

Of the 350 addresses, 327 apparently were valid. Of the 327 people who received the questionnaire, 202 returned the questionnaire $(61 \%$ response). More women than men returned the questionnaire (116 versus 86). Of the 202 respondents, 46 people applied for insurance in the period between being screened and the study $(23 \%)$. Of those 46 people who tried to get insurance, 17 encountered problems ( $37 \%$; see table 1 ).

The type of problem most often encountered was the requirement to pay a higher premium, the requirement to undergo additional medical tests, the requirement to let the insurance company scrutinise medical records, and complete rejection of the application for insurance. If stated, the argument of the insurance companies to support their policy was the fact that the applicant had FH. Surprisingly, most (13 of 17) people who encountered problems applied for a life

\section{Key points}

- In the Netherlands guidelines and legislation exist on the use of genetic test information.

- This study shows that participants of a genetic screening programme still encounter unanticipated insurance problems.

- It is not clear why these problems occur: whether insurance companies ask questions regarding genetic testing or questions that can be read as such, or that individuals themselves give more information than asked for.

- We conclude that guidelines and legislation on genetic information are but a prerequisite and that education of all involved is equally important.

insurance well below the cut off points stated in the moratorium and the Act on Medical Examinations, which implies that the applicants were not obliged to provide the insurance company with information on genetic testing.

The question is whether the encountered problems occur because these people have a genetic mutation for FH. Another possibility is that problems occur because of their increased cholesterol level, as this is the most likely confounder in this population of mainly asymptomatic carriers and non-carriers. The table shows the association between an increased cholesterol level, the presence of a genetic mutation for $\mathrm{FH}$ and the occurrence of problems among the 46 respondents who applied for insurance.

We apply a $6.5 \mathrm{mmol} / \mathrm{l}$ cut off in cholesterol concentration because insurance companies consider people with a cholesterol level above this cut off point to be at increased risk of death. We used log linear analysis with having problems as the dependent variable and the mutation and cholesterol concentration as independents. Correlation between the independent variables was assumed. We looked for the most economic model that would fit the data-that is, the model with the fewest interactions. The model in which only the mutation is associated with having problems fitted the data (likelihood ratio $\chi^{2}=2.32, \mathrm{df}=2, \mathrm{p}=0.31$ ), while the model in which only the cholesterol level is associated with having problems did not (likelihood ratio $\chi^{2}=6.70, \mathrm{df}=2, \mathrm{p}=0.035$ ). Therefore, from this analysis it seems that encountered problems primarily relate to the presence of the FH mutation. If this were true, this policy would be at discrepancy with the current scientific state of the art, which acknowledges the cholesterol (level) to be the transmitter or carrier of the higher mortality risk associated with FH. However, given the small sample size and therefore the limited power of this analysis, as well as the lack of data on other possible confounders, a final conclusion regarding this issue cannot be drawn.

\section{DISCUSSION}

This empirical study has shown that in the Netherlands, which combines relevant guidelines and legal arrangements on the use of genetic testing in insurance affairs, participants of a genetic screening programme encounter unanticipated insurance problems. Although the number of people exposed to an insurance procedure is small (46) because of the limited follow up time of tested persons, the proportion of those encountering problems (a third) is worrisome, even if one accounts for some selective response. Moreover, others reported similar data. ${ }^{10}$

Even more disturbing was the presence of problems in cases where the Act on Medical Examinations explicitly rules out a role for genetic test information. From our study it is not clear why these problems occur-that is, whether insurance companies ask questions regarding genetic testing or questions that can be read as such, or applicants present genetic test information unasked. The latter may be particularly true 
for the relatively uneducated. When asked for, only $14 \%$ of the individuals knew about the Act on Medical Examinations or the moratorium. The line of questioning or the repeated statement in questionnaires that insurance coverage is lost if the information supplied is incorrect may induce over-response by the applicant. Furthermore, compared with questionnaires designed for scientific purposes (for example, health risk measurement in surveys), the existing insurance questionnaires frequently appear ambiguous, providing the applicant no clues as how to interpret questions.

Our main conclusion is that implementation of the Act on Medical Examinations requires more control on its procedural execution. Moreover, the participants of a genetic screening programme, the public in general, but also those engaged in the insurance acceptation process should be educated about the existing guidelines regarding genetic testing. At this stage responsibilities are ill defined. Recently, the screening organisation included explicit information on the issue before the testing procedure. Our case study shows that the presence of national guidelines and regulations on the (mis) use of genetic information is but a prerequisite for appropriate use of genetic information in the context of insurance. Education of all involved, including the screenee/patient is equally important.

\section{ACKNOWLEDGEMENT}

The authors would like to thank G J Bonsel for his comments on an earlier draft of this paper

Funding: this study was funded by the Health Research and Development Council (grant number 28-2751).

Conflicts of interest: none.

\section{Authors' affiliations}

P J Marang-van de Mheen, M C van Maarle, M E A Stouthard, Department of Social Medicine, Academic Medical Centre, Amsterdam, the Netherlands

\section{REFERENCES}

1 Motulsky GA. Genetic aspects of familial hypercholesterolemia and its diagnosis. Arteriosclerosis 1989;9 (suppl 1):13-7.

2 Goldstein JL, Schrott HG, Hazzard WR, et al. Hyperlipidemia in coronary heart disease. II. Genetic analysis of lipid levels in 176 families and delineation of a new inherited disorder, combined hyperlipidemia. $J$ Clin Invest 1973;52:1544-68.

3 Slack J. Inheritance of familial hypercholesterolemia. Atherosclerosis Rev 1979:5:35-66.

4 Goldstein JL, Hobbs H, Brown M. Familial hypercholesterolemia. In: Scriver CT, Beaudet AL, Sly WS, et al, eds. The metabolic basis of inherited disease. New York: McGraw-Hill, 1989:1981-2030.

5 Scientific Steering Committee on behalf of the Simon Broome Register Group. Mortality in treated heterozygous familial hypercholesterolemia: implications for clinical management Atherosclerosis 1999;142:105-12.

6 Kastelein JJP, Defesche JC. National screening of patients with familial hypercholesterolemia by the Stichting Opsporing Erfelijke Hypercholesterolemie (StOEH). [In Dutch]. Amsterdam: StOEH, 1994.

7 Umans-Eckenhausen MAW, Defesche JC, Scheerder RLM, et al. Screening of patients with familial hypercholesterolemia in the Netherlands. [In Dutch]. Ned Tijdschr Geneeskd 1999;143:1157-61.

8 Schrijivers AJP. Health and health care in the Netherlands. A critical self-assessment by Dutch experts in the medical and health services. Maarssen: Elsevier/De Tijdstroom, 1998.

9 Morrison PJ. Implications of genetic testing for insurance in the UK. Lancet 1998;352:1647-8.

10 Low S, King S, Wilkie T. Genetic discrimination in life insurance: empirical evidence from a cross sectional survey of genetic support groups in the United Kingdom. BM 1998;317:1632-5 